Squibb, Johnson \& Johnson, Novartis, Pfizer, Reckitt Benkiser, and Roche

DOI: 10.1136/annrheumdis-2019-eular.7415

\section{FRI0548 EFFICACY AND SAFETY OF TOCILIZUMAB IN SYSTEMIC AND POLYARTICULAR JUVENILE IDIOPATHIC ARTHRITIS - DATA OF THE BIKER REGISTRY}

Ariane Klein ${ }^{1}$, Gerd Ganser ${ }^{2}$, Ralf Trauzeddel ${ }^{2}$, Kisten Minden ${ }^{2}$,

Christoph Rietschel ${ }^{2}$, Jasmin Kuemmerle-Deschner ${ }^{2}$, Gerd Horneff ${ }^{1} .{ }^{1} B I K E R-$

Registry, Sankt Augustin, Germany; ${ }^{1}$ BIKER-Registry, Sankt Augustin, Germany

Background: Since 2011 Tocilizumab is approved for systemic juvenile idiopathic arthritis (JIA) and since 2013 for polyarticular JIA

Objectives: To describe efficacy and safety of Tocilizumab in clinical practice in polyarticular (pJIA) and systemic JIA (sJIA) patients using the German Biologics registry (BiKeR)

Methods: Baseline demographics and disease activity parameters have been documented. Efficacy was determined using the JADAS10 prospectively. Safety assessments were based on adverse events reports (AE) processed according to MedDRA

Results: Until October 1, 2018, 345 JIA patients treated with Tocilizumab were registered, representing 635 patient-years (PY) of observation. The cohort treated with Tocilizumab had experienced disease duration of 5.5 $+/-4.3$ years (mean+/-SD) for sJIA and 5.9+/-4.1 years for pJIA. sJIA/pJIA patients received pretreatment with MTX $72 \% / 96 \%$, Anakinra $23 \% / 1 \%$, Adalimumab $4 \% / 60 \%$, Etanercept $30 \% / 69 \%$, Canakinumab $2 \% / 0 \%$. Concomitantly, sJIA/pJIA patients received NSAIDs $64 \% / 57 \%$, systemic steroids $72 \% / 35 \%$, MTX $55 \% / 54 \%$, other DMARDS $4 \% / 8 \%$. At last follow-up, $63 \% / 60 \% / 51 \% / 43 \%$ of sJIA and $56 \% / 49 \% / 40 \% / 30 \%$ of pJIA patients reached JIAACR30/50/70/90 criteria. After 2 years of treatment JADAS remission was reached by $50 \% / 43 \%$ and JADAS minimal disease activity by $67 \% / 67 \%$.

586 AE were reported during exposure plus 90 days of observation. The rate was significantly higher in SJIA (104/100PY [95\% Cl 92-119]) than in pJIA patients (79 [79-90]; RR 1.3; $p=0.003) .75$ qualified as serious $A E$ (SAE) with a higher rate in SJIA (22[16-29] vs. 8 [5-12], RR 2.6; $p<0.001)$. The most frequent $A E$ in the $s J I A / p J I A$ cohort were grouped in the MedDRA SOC infections and infestations $(n=92 / 76)$. Compared to pJIA, rates were significantly higher in sJIA patients for blood and lymphatic (RR 2.4; $p=0.019$ ), immune system (RR 2.6; $p=0.04$ ), infections \& infestations (RR 1.7, $\mathrm{p}<0,001$ ) and nervous system disorder (RR 2.6, $p=0.012$ ) and lower for general and administration site (RR $0.4 ; p=0.023$ ). 169 patients (49\%) discontinued treatment, $17 \%$ due to remission, $22 \%$ due to lack of efficacy and $9 \%$ because of intolerance.

Conclusion: The analysis adds to the established safety profile of tocilizumab in paediatric patients with systemic \& polyJIA. Differences were noted between pJIA and SJIA cohorts, the latter with higher rates of total number of adverse events, serious $\mathrm{AE}$, infections and cytopenias, probably due to higher doses or shorter application intervals. No new safety signals specific to the paediatric population were identified in this large cohort of JIA patients.

\begin{tabular}{|c|c|c|c|}
\hline & SJIA $(n=109)$ & $\begin{array}{c}\text { pJIA } \\
(n=239)\end{array}$ & $\mathrm{RR} / \mathrm{p}$ \\
\hline All AE (rate[95\%Cl]) & $\begin{array}{l}234(104[92- \\
119])\end{array}$ & $\begin{array}{l}252(79[70- \\
90])\end{array}$ & $\begin{array}{l}0.76 / \\
0.003\end{array}$ \\
\hline SAE & $\begin{array}{l}49(22[16- \\
29])\end{array}$ & $26(8[5-12])$ & $\begin{array}{c}0.38 / \\
<0.001\end{array}$ \\
\hline blood \& lymphatic system ${ }^{1}$ & $20(9[6-14])$ & $12(4[2-7])$ & $\begin{array}{l}0.42 / \\
0.019\end{array}$ \\
\hline gastrointestinal disorders & $13(6[3-10])$ & $30(9[7-14])$ & n.s. \\
\hline general disorder \& administration site condition ${ }^{2}$ & $9(4[2-8])$ & $\begin{array}{c}30(9(7- \\
14])\end{array}$ & $\begin{array}{l}2.4 / \\
0.023\end{array}$ \\
\hline immune system disorders ${ }^{3}$ & $13(6[3-10])$ & $7(2[1-5])$ & $\begin{array}{l}0.38 / \\
0.040\end{array}$ \\
\hline infections and infestations ${ }^{4}$ & $\begin{array}{l}92(41[33- \\
50])\end{array}$ & $\begin{array}{l}76(24[19- \\
30])\end{array}$ & $\begin{array}{c}0.59 / \\
<0,001\end{array}$ \\
\hline injury, poisoning and procedural complications & $7(3[1-7])$ & $10(3[2-6])$ & n.s. \\
\hline $\begin{array}{l}\text { neoplasms benign, malignant and unspecified (incl } \\
\text { cysts and polyps) }\end{array}$ & $1(0[0-3])$ & $2(1[0-3]$ & n.s. \\
\hline nervous system disorders ${ }^{5}$ & $20(9[6-14])$ & $11(3[2-6])$ & $\begin{array}{l}0,39 / \\
0.012\end{array}$ \\
\hline skin and subcutaneous tissue disorders & $11(5[3-9])$ & $11(3[2-6])$ & n.s. \\
\hline
\end{tabular}

MedDRA-SOC: Rates are outlined as number during exposure +90 days follow up, censored if an alternative biologic has been applied. 1 MAS, neutron-, thrombocytopenia; 2 nausea, aphthosis; 3 allergic reactions; 4 viral and bacterial infections; 5 seizures
REFERENCES:

[1] Horneff G, et al. Arthritis Res Ther. 2016 Nov 24;18(1):272

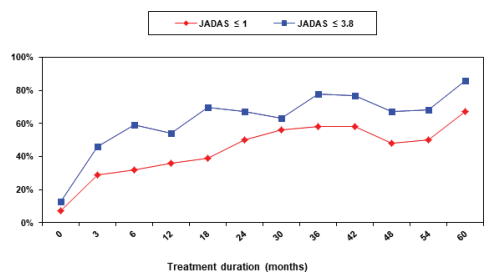

SJIA

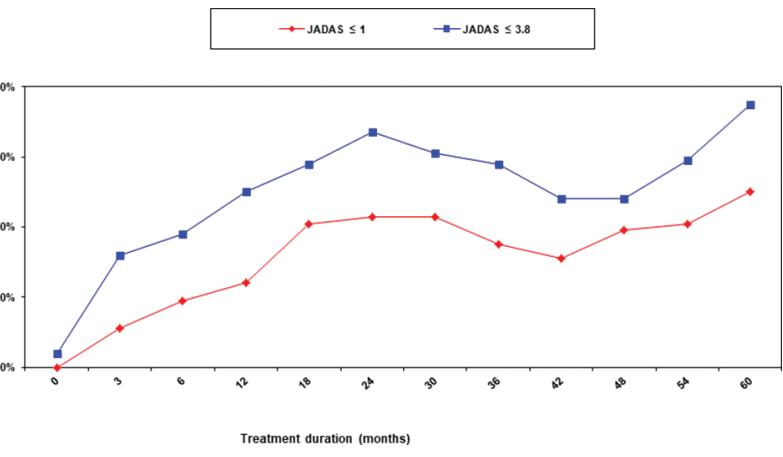

polyJIA

Acknowledgement: BIKER and the documentation of the treatment with biologics is partially sponsored by Chugai and Roche, Germany

Disclosure of Interests: Ariane Klein: None declared, Gerd Ganser: None declared, Ralf Trauzeddel: None declared, Kisten Minden Grant/research support from: Pfizer, Abbvie, Christoph Rietschel: None declared, Jasmin Kuemmerle-Deschner Grant/research support from: Jasmin KuemmerleDeschner is an employee of University of Tuebingen, Germany, and received consultants/speakers fees from Novartis and SOBI pharmaceuticals and grant support from SOBI and Novartis., Consultant for: Jasmin Kuemmerle-Deschner is an employee of University of Tuebingen, Germany, and received consultants/speakers fees from Novartis and SOBI pharmaceuticals and grant support from SOBI and Novartis., Speakers bureau: Jasmin Kuemmerle-Deschner is an employee of University of Tuebingen, Germany, and received consultants/speakers fees from Novartis and SOBI pharmaceuticals and grant support from SOBI and Novartis., Gerd Horneff: None declared

DOI: 10.1136/annrheumdis-2019-eular.2109

\section{FRI0549 \\ SARILUMAB, A HUMAN MONOCLONAL ANTIBODY TO THE INTERLEUKIN-6 (IL-6) RECEPTOR, IN POLYARTICULAR-COURSE JUVENILE IDIOPATHIC ARTHRITIS (PCJIA): A 12-WEEK MULTINATIONAL OPEN-LABEL DOSE-FINDING STUDY}

Fabrizio De Benedetti ${ }^{1}$, Inmaculada Calvo Penadés ${ }^{2}$, Nadina E. Rubio Pérez ${ }^{3}$, Alexey Maschan ${ }^{4}$, Pierre Quartier ${ }^{5}$, Zbigniew Żuber ${ }^{6}$, Marina Stanislav 7 , Raul Barria ${ }^{8}$, Daniel Clemente Garulo ${ }^{9}$, Gabriel Vega Cornejo ${ }^{10}$, Nancy Liu ${ }^{11}$ Christine Xu ${ }^{11}$, Angeliki Giannelou ${ }^{12}$, Bolanle Akinlade ${ }^{12}$, Lydie Baret-Corme ${ }^{13}$, on behalf of DRI13925 investigators. 'O Spedale Pediatrico Bambino Gesù, Rome, Italy; ${ }^{2}$ Instituto de Investigación Sanitaria La Fe, Valencia, Spain; ${ }^{3}$ University Hospital Dr. José Eleuterio González, Monterrey, Mexico; ${ }^{4}$ Centre of Pediatric Hematology, Oncology and Immunology, Moscow, Russian Federation; ${ }^{5}$ Necker Hospital, Paris, France; ${ }^{6}$ Andrzej Frycz Modrzewski Krakow University, Krakow, Poland; ${ }^{7}$ VA Nasonova Research Rheumatology Institute, Moscow, Russian Federation; ${ }^{8}$ Bioreuma, Concepción, Chile; ${ }^{9}$ Hospital Infantil Universitario Niño Jesús, Madrid, Spain; ${ }^{10} \mathrm{CREA}$ de Guadalajara, Jalisco, Mexico; ${ }^{11}$ Sanofi, Bridgewater, NJ, United States of America; ${ }^{12}$ Regeneron, Tarrytown, NY, United States of America; ${ }^{13}$ Sanofi, Paris, France

Background: Sarilumab blocks IL-6 from binding to membrane and soluble IL-6 receptor-á. Sarilumab is approved for adults with rheumatoid arthritis (RA) and is being investigated in a Phase 2 trial (NCT02776735) 